\title{
The Design and Realization of Personal Internet Banking System Based on JSSM
}

\author{
Zhang $\mathrm{Li}^{*}$ \\ College of Computer Engineering , Jiangsu University of Technology, Chang Zhou, China
}

\begin{abstract}
For the sake of solving the abuse of the Personal internet banking, saving the marketing cost, increasing the efficiency of customers' life, This article raised a personal internet banking system based on the structure of jSSM. Firstly, in terms of usability, it adopted the technique which combined jquery and esayui together, therefore, the front desk of Windows is Metro style that users only need to do few buttons-operations, and then the operations can be done. Secondly, in terms of security, it adopted administrator's three layers check, combining the asynchronous validation and the regular expression of jQuery. Lastly, in the background desk, it adopted jSSM to enforce not only the system development efficiency and also raised the maintainability and scalability of Personal internet banking system.
\end{abstract}

Keywords: Business hierarchical management, Jquery structure, personal internet banking, UML modeling language.

\section{INTRODUCTION}

Personal internet banking means to provide services like account enquiry, transfer money, investment, online payment, etc. This system makes customers to safely manage current and fixed deposit, cheque, credit card and personal investment and so on without going out. There are two kinds of clients of personal internal banking; they are registered client and nonregistered client. Registered client can be divided into counter registered client and self-service registered client by registration way, also can be divided into certificate client and non-certificate client by that if they apply for the certificate. Personal online bank can be called virtual bank counter on internet. From business logic, most personal business of bank can be finished by users on personal online bank. Therefore, security of personal online bank is the most important part. In this article, administrator verification is applied to ensure the safety of transaction that different level administrators verify the same business for three different levels. However the administrator cannot check the detailed information of this deal. Then the security of transaction from individual privacy can be ensured, and it also can prevent malicious transfer and misoperation. Meanwhile, to guarantee the completeness of this system, it is necessary to comprehend the problem from the perspective of both client and banker. For clients, they don't understand the work flow of bank; hence, they only need favorable interactive interface and easy and simple operation hints. And for bankers, back stage administrators need several easy buttons to realize the powerful functions. Consequently, this article put forward the framework technology based on jQuery EasyUI+ Struts+Spring+Mybatis (shorten as JSSM) to realize the personal online bank system. First of all, it applied the combination of jquery and esayui on business interface, main interface

*Address correspondence to this author at the College of Computer Engineering, Jiangsu University of Technology, Chang Zhou, China;

E-mail: zhangli_3913@163.com imitates Metro of Windows, which makes the system more modern. All the business flow needs to fill the applications and most application is embodied as drop-down box, which is more convenient and faster. Secondly the security is ensured by administrator verification and system automatically confirmation. Administrators verification applied the three layers verification and for system automatically confirmation, it applied jQuery asynchronous verification and regular expression. Thirdly, to guarantee the backstage of the system to finish the business operation successfully, it adopted Struts + Spring + Mybatis, which solved the problems of: (1) simplified the writing of business components and reusing of codes. (2) reduced the coupling of each layers, and clarify the responsibility of each layer which enhanced the extendibility, transportability and maintainability of the system. (3) it raised the efficiency of development and the convenience of maintenance. Lastly, it is necessary to show the structure of this paper: (1) it analyzed the business of personal online bank, described its system scope and business flow. (2) It adopted JSSM, and it explained the relationship of them. (3) It is proved that it is reasonable to use JSSM with examples in this article, and it proved that this framework can solve the problem of coexistence of system usability and security of this personal online bank.

\section{THE ANALYSIS AND DESIGN OF SYSTEM}

\subsection{The Analysis and Design of Personal Online Bank use Case}

During the process of need analysis of personal online bank, there is a problem needs to be solved that both users and developers ha to know that what kind of system they are going to develop. Therefore, need analysis has to be done from two sides; they are normal user (client) and banker (administrator). For the client, usability means that the personal bank system should have a nice interactive interface, simple ad useful functions, which can be easily operated for 


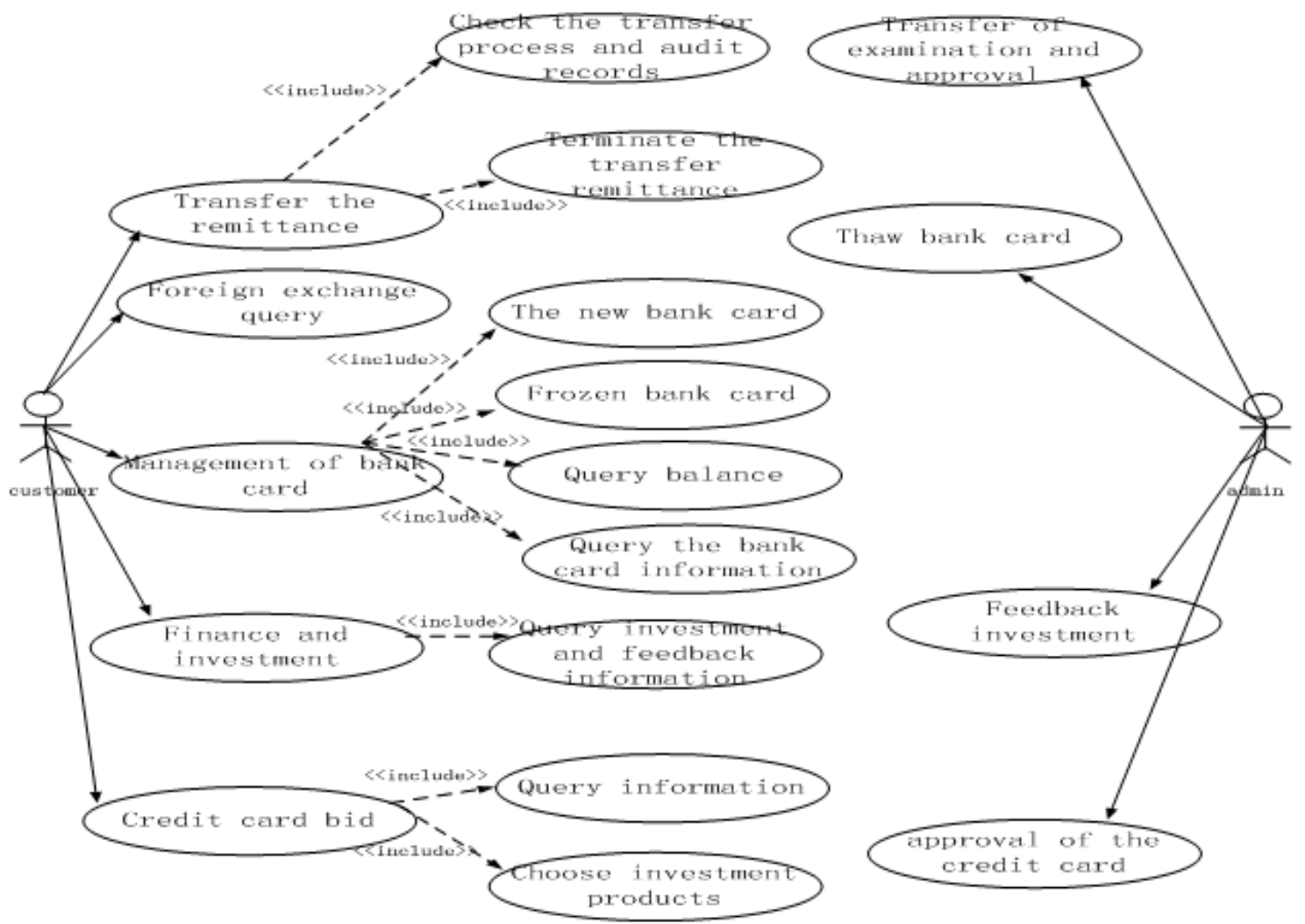

Fig. (1). The use case of personal online bank system.

investment, transferring, and checking. After the operation, these operation results can be checked. Among these, the most important thing is how to ensure the security of this system, and how to ensure the safety of investment and transferring. Moreover, purity of the transaction has to be ensured, that means except the users themselves, no one can check the information and figure of this transaction. For the administrator, it is very vital to do the three layers verification. The key work point of this system is how to make the security control as a work flow. Besides, the actual feedback of investment to users, approval of the credit card application, are also the main functions of this system. And the function of administrators is constituted by the users operation. It mainly includes examination and verification to the submitted information materials of users and latter processing and maintenance. From the above, it is easy to know that the customer need is the core point of the whole system. The needs can be analyzed form both usability and safety sides. And how to realize the security and security flow has to be considered from the perspective of administrators. The use case of personal online bank system $[1,2]$ is shown in Fig. (1).

\subsection{System Process Design}

From 1.1, it is obvious that this system can be visited by three kinds of persons: visitor, user, and administrator. Visitor can scan and experience all the services except business function, includes: front page, registration, and members club and points store. And users can do business operation on the basis of visitor, and meanwhile they can register to be vip and use the points to exchange products. Administrator entered the system; they can manage the related business flow. The system flowchart is shown in Fig. (2). This flowchart is designed to three kinds of people; visitor can scan most webpages and read the latest news and information, and further to register to be user. User can log in the system and do business operations. Administrator serve to user, and make the hierarchical approval to ensure the security.

\subsection{The Design of Entity Relationship of System}

The system is completely managed about the users' use, enter and exit. It can synthetically reflect personal capital's increase, decrease and variation, and provide product lifecycle management and tracking. The physical data Figure matic figure of this system has been shown in Fig. (3) (it has been modified and simplified). This Figure matic figure revealed the logic relationship and database structure of this personal online bank system. From Fig. (3), ACCOUNT takes up the main position, and it supplies data support to other functional table. Specifically, one user only has one account, but one account can has several bank cards and credit cards, however every card has its serial numbers and card number which can keep the uniqueness and non-dull. These card numbers are the key to carry out the business operation. It can make transferring, invest, payment, freezing and unfreezing. In the same way, it is certainly to find the users and accounts by the card numbers, and some other latter operations can be done also, for example, messages' recursion, freezing and unfreezing. Besides, the relationship between VIP table and EVENTS table is also one to many, these two tables states that one person changes from a user to a vip can exchange his points to many products in the points store. The points are the very important attribute in VIP tables. ADMIN table is used to reserve administrator's account 


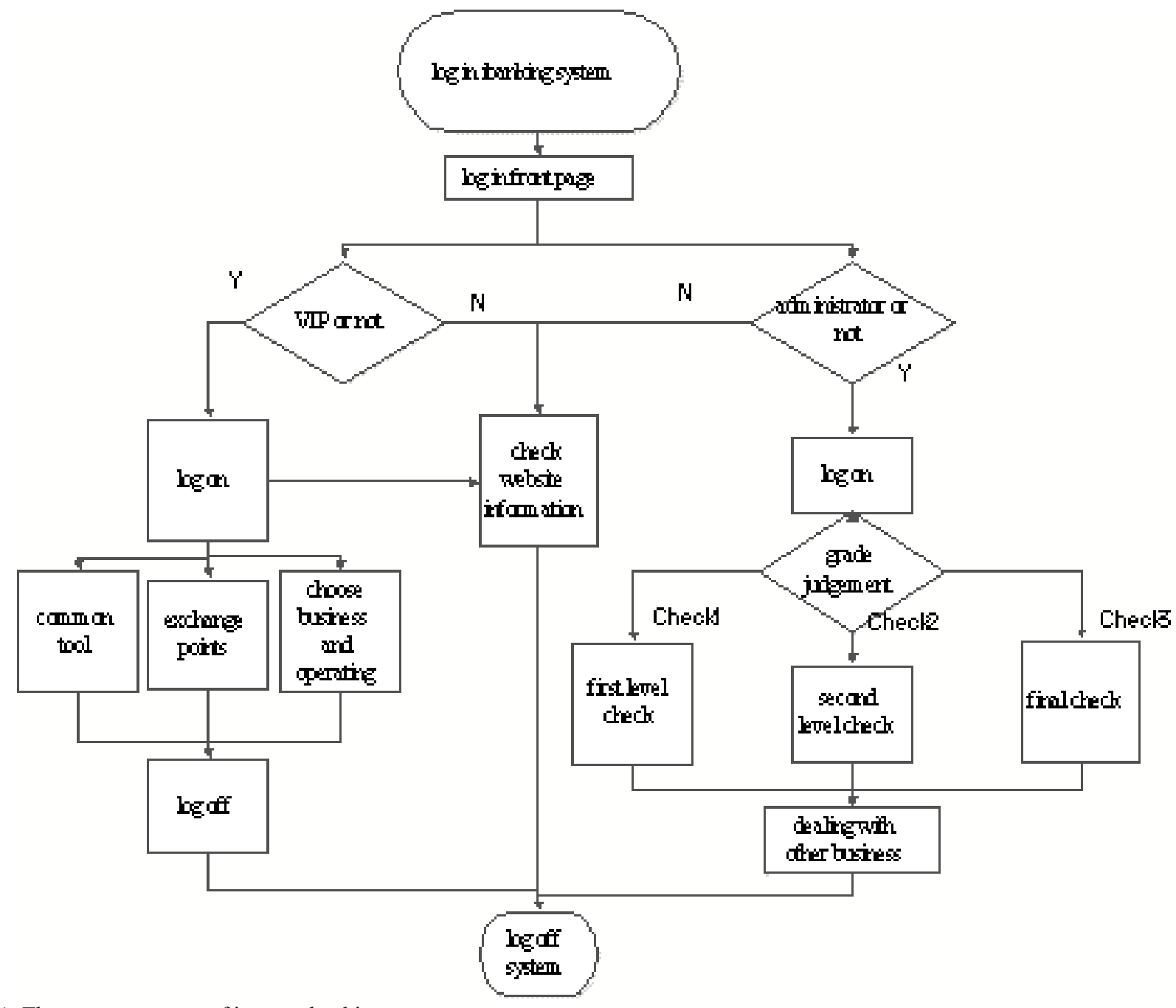

Fig. (2). The system process of internet banking.

and password, has no relationship with other tables. ADMIN $\log$ in, it only needs to operate on other latter table data in back stage, which indeed realized the isolation between banker and money.

\section{THE DESIGN OF PERSONAL ONLINE BANKING SYSTEM ARCHITECTURE}

When design the personal online banking system platform, we take MVC+JSSM hierarchical design model [3] and system flowchart as the reference, they are presentation layer, control layer, business layer, model layer, DAO factory pattern and database layer. It is leading by Struts, combines with Spring+Mybatis and factory design pattern $[4,5]$, embodied the MVC systemic level. It put the business rule and database access in the middle layer to process, therefore the client side doesn't need to interact with data directly, but to build the relationship with middleware through controller, and realize the interaction with database by middleware. To explain this relationship clearer, there is a framework shown in Fig. (4). From Fig. (4), no matter he is user or administrator, he can do all the operations by Browser. Browser as the explore is the feedback tool in presentation layer. All the operations can be done by scanning and clicking on the buttons and interface in presentation layer by browser.

\subsection{Presentation Layer}

The main responsibility of presentation layer is to present and feedback some forms and data by JSP. IN mvc design pattern, it is like VIEW layer. In this layer, its main task is how to make the VIEW more beautiful. Here, the strong function of jquery and jquery easyui needs to be pointed out. The function and meaning of Jquery in front stage is its plasticity, which can freely create and combine the codes to reach the result what they want through the developer's thinking. The function of jquery easyui is to make the step much easier and more convenient.

\subsection{Control Layer}

The main responsibility of control layer is to use the servlet in JSP table, and to find its position in Web.xml, and finish the operation. Servlet, as the core of control layer, it controls the transmitting and matching of the data and tables, and it also packages the data. It is as the Controller in MVC design model. In this system, it reads fields in front stage and send it to back stage for data checking. The returned value is encapsulated as a List and hand to VIEW for traversal and display. 


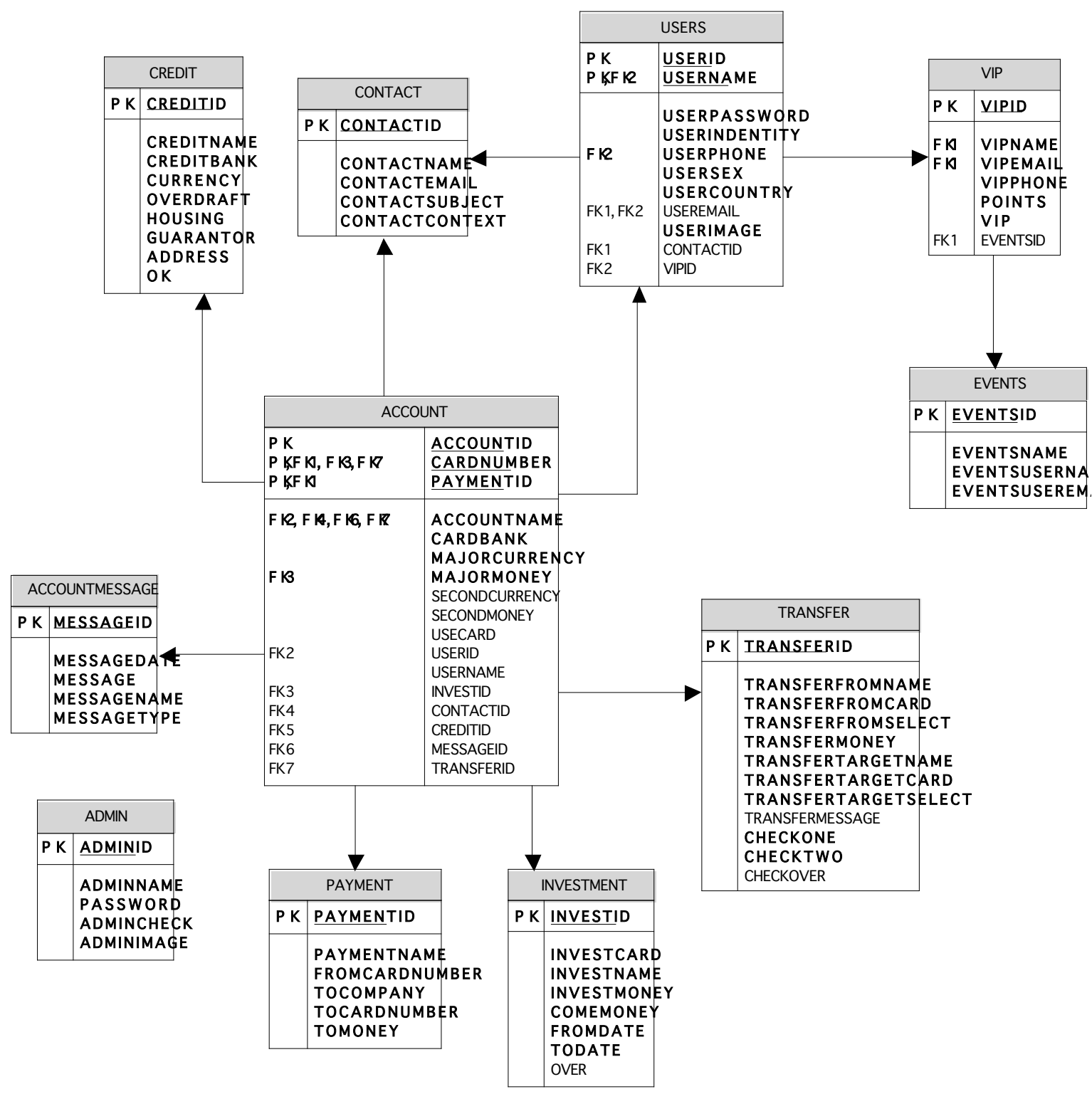

Fig. (3). The physical data Figure matic figure of personal online bank.

\subsection{Business Layer}

The main function of business layer is to continue, when Servlet in control layer finished download task, the data filled in front satge tables handed to Service in business layer for the next step operation. The function of service is similar to a communication platform of peripheral interface. The business in front stage can be handed to subordinate logic layer DAO for specific operating. After DAO's checking, deleting and inserting, it will return a value or a character string to Service, and will be transferred to control layer by Service, then it will be encapsulated by control layer and traverse to front stage tables.

\subsection{Data Layer}

The task of data layer [6] is to do operations to database. In the system, when data transferred to DAO, it has to return data and do the latter processing. When the inquiry is successful, it will return a Boolean value, true means find the message and feedback, false means there is no data, and no feedback. The specific feedback information is the List data; it will be encapsulated and traversed to front stage tables.

\section{DESIGN AND COMPLEMENTATION FOR KEY FUNCTIONS OF PERSONAL ONLINE BANKING}

\subsection{Design of Registration and Loginand the Implemen- tation of Jquery}

To realize the registration and login functions [7] of personal online banking, it needs to consider from two sides. One is that the visitor registered to be user, and log in the system and do some operations. Another is that administrator $\log$ in the system and do some managements. There is no registration for administrator for the sake of security. For a high security system, an administrator's adding needs many authentications. Therefore, in this system, the finally decision has to be made by DBA for authenticating and adding. The flow path of registration and login of user is shown in Fig. (5). 


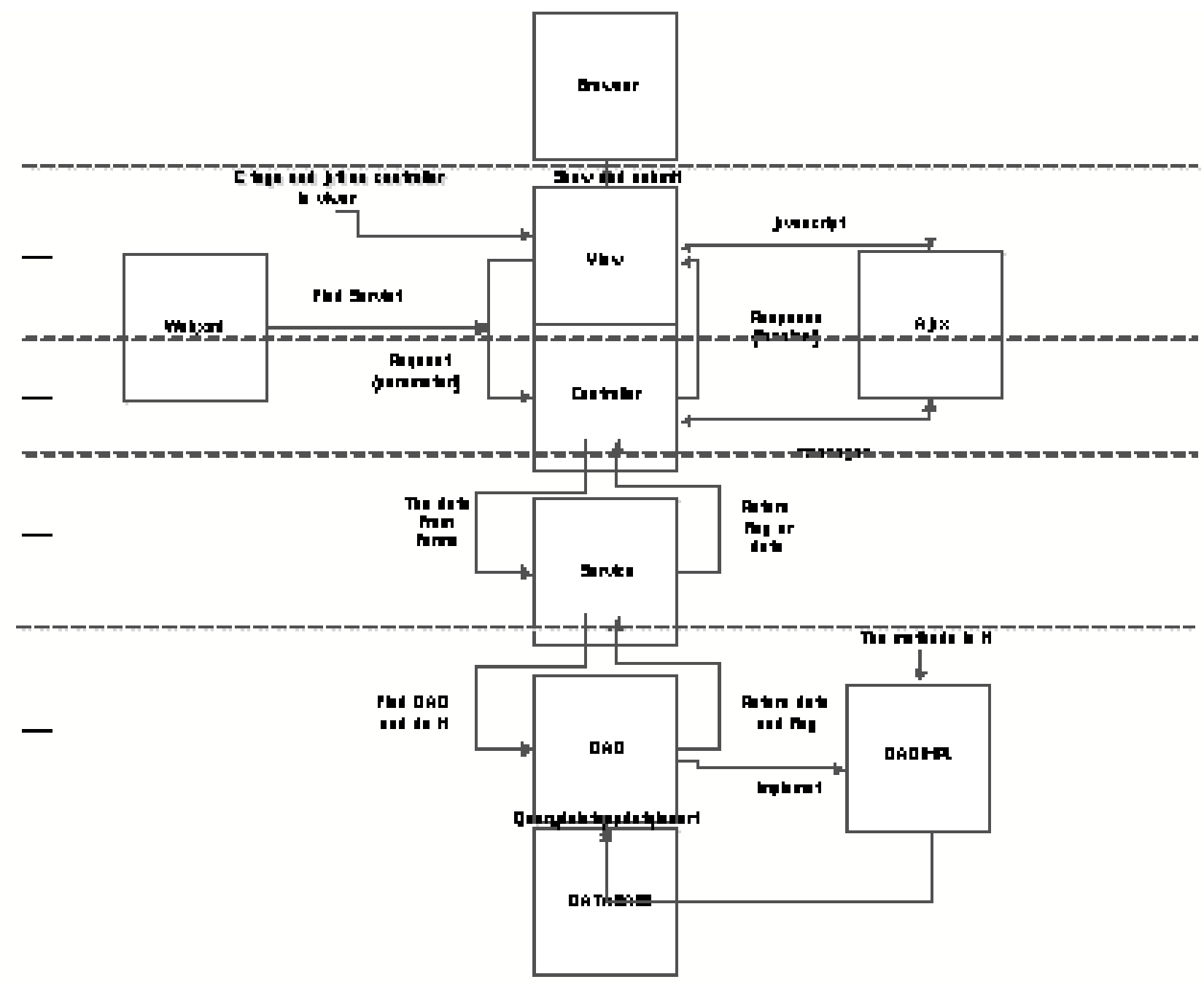

Fig. (4). The design of personal online banking system framework flowchart.

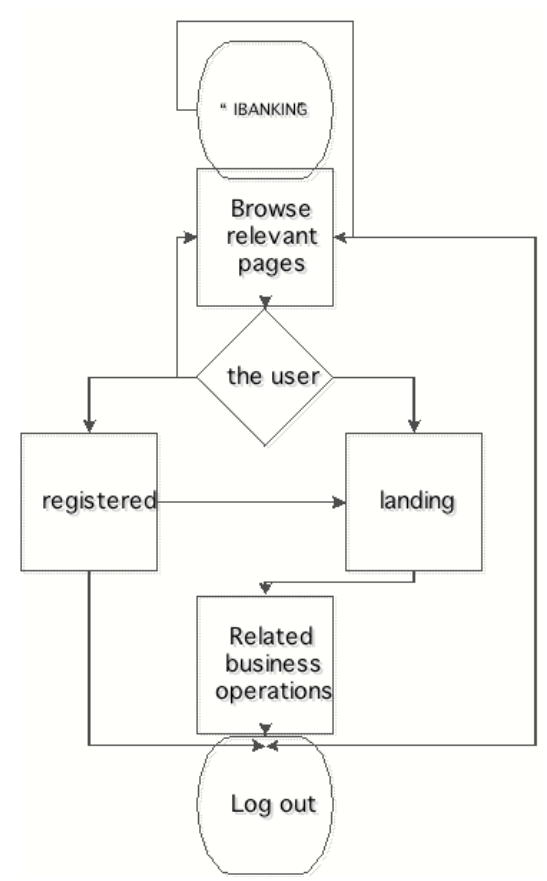

Fig. (5). The flow path of registration and login of user in personal online banking system.
In this function, it is necessary to explain the implementation of JQuery asynchronous verification. Visitor log in the registration page, and do registration, the user name will be the main key of USER table, with uniqueness and non-null. It means that if one user name has been registered, it cannot be register for the second time. In order to do the registration easily, it is vital to add JQuery in the input field for friendly reminder. The codes are in Table $\mathbf{1}$, there are delete and changes on these codes.

\subsection{The Implementation and Design of Administrator's Hierarchical Management}

Administrator log on the system in the similar way of users, there is no registration model for administrator, therefore, they only need to input right account number and password, and then they can enter the administrator interface. What needs to pay attention to is that every administrator has its own administrative level, so different administrators do the different level business examinations. In this functional model, the operation process and design of the hierarchical management will be emphasized. Hierarchical management $[8,9]$ mainly uses the $\mathrm{c}$ tag technology. The login flowchart of administrator is shown in Fig. (6). This technology can be used to judge the type of users, users or visitors, visitor jump 
Table 1. Part of the codes for user registration of personal online banking.

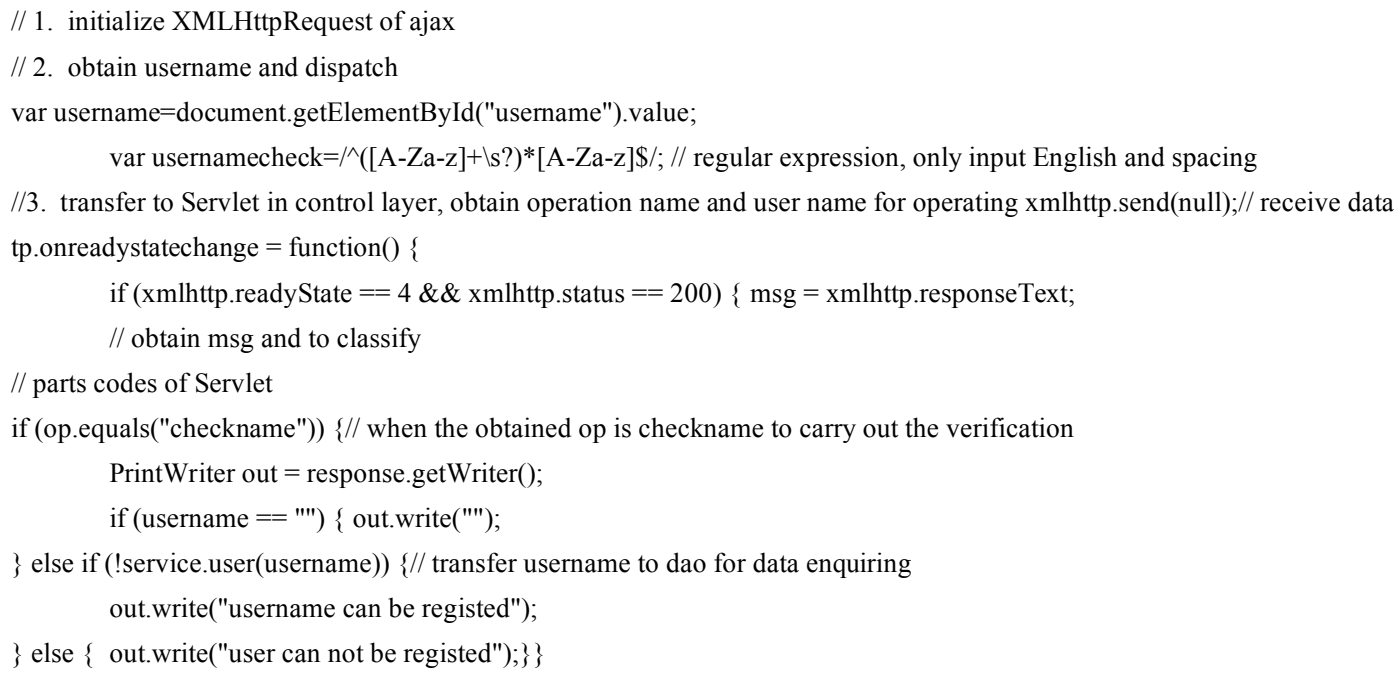

Table 2. The classification skip codes of administrator of personal online bank.

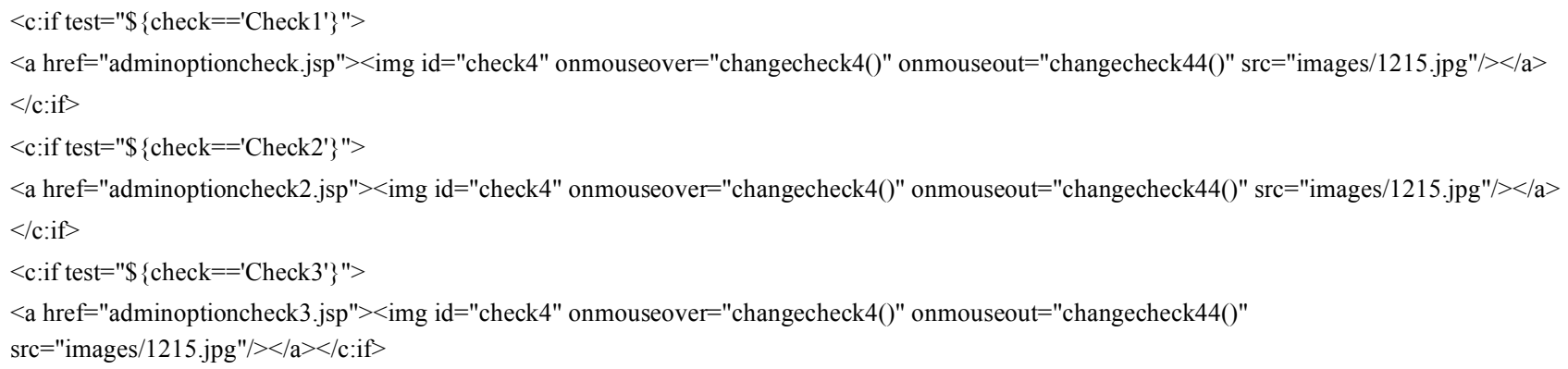

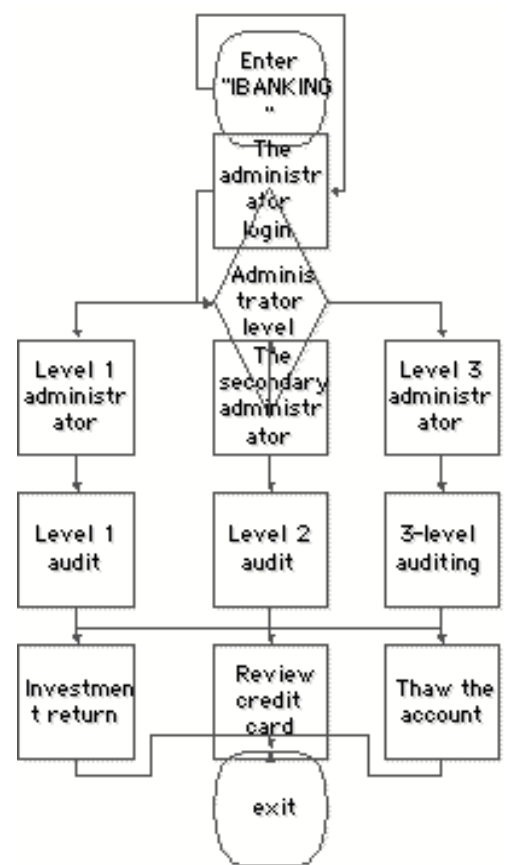

Fig. (6). The login flowchart of administrator of personal online banking system. to the blank, and user can log in personal service center and do the personal procedure and business. In total, it is a functional block of classify skip. The codes are in Table 2 .

\subsection{Design and Implementation of Transferring and Remitting}

In all the business of personal online bank, the most important business is transferring and remitting. Transferring and remitting is the very simple input and output operation, it is very different from investment, because there is no fixed payback, it needs to make sure if the money has been deducted or reached to another account. In this business, continually getting information is very significant; therefore, how to do the pass back work for information is the key point. In this system, the main safety verification way is the three layer administrator asynchronous verification, which can prevent the transferring of illegality. Meanwhile, it can monitor the response of user, when user find any unusual phenomenon they can call service hot line for help to stop the transaction. There is another process is also very important in this function, that is the flowchart of examination and approval which can let user know that how many layer verification has been finished, and what the status is. Hence, the system designs another data table to record the information of users. In the same time, it will return the information to 


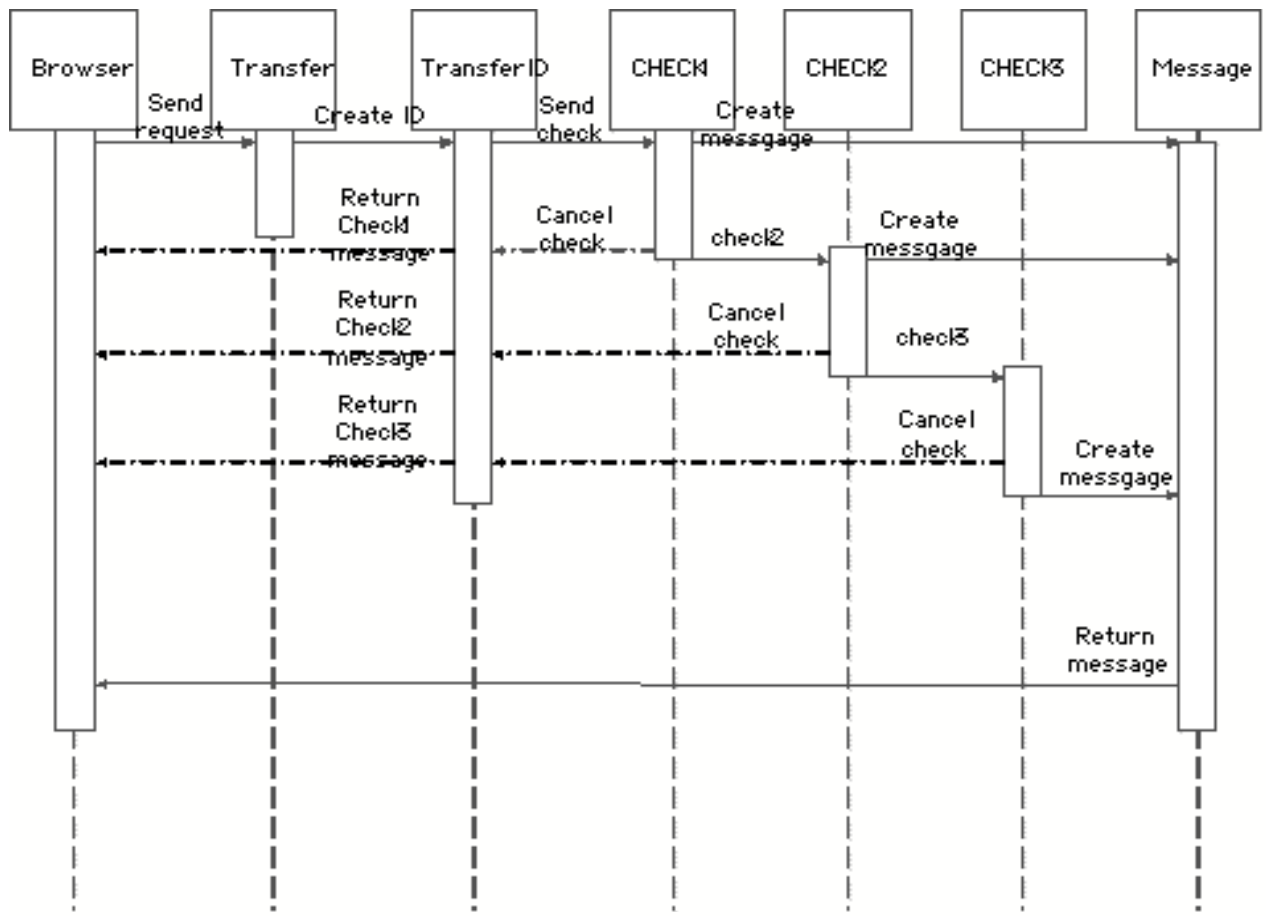

Fig. (7). Sequence chart of transaction on personal online banking system.

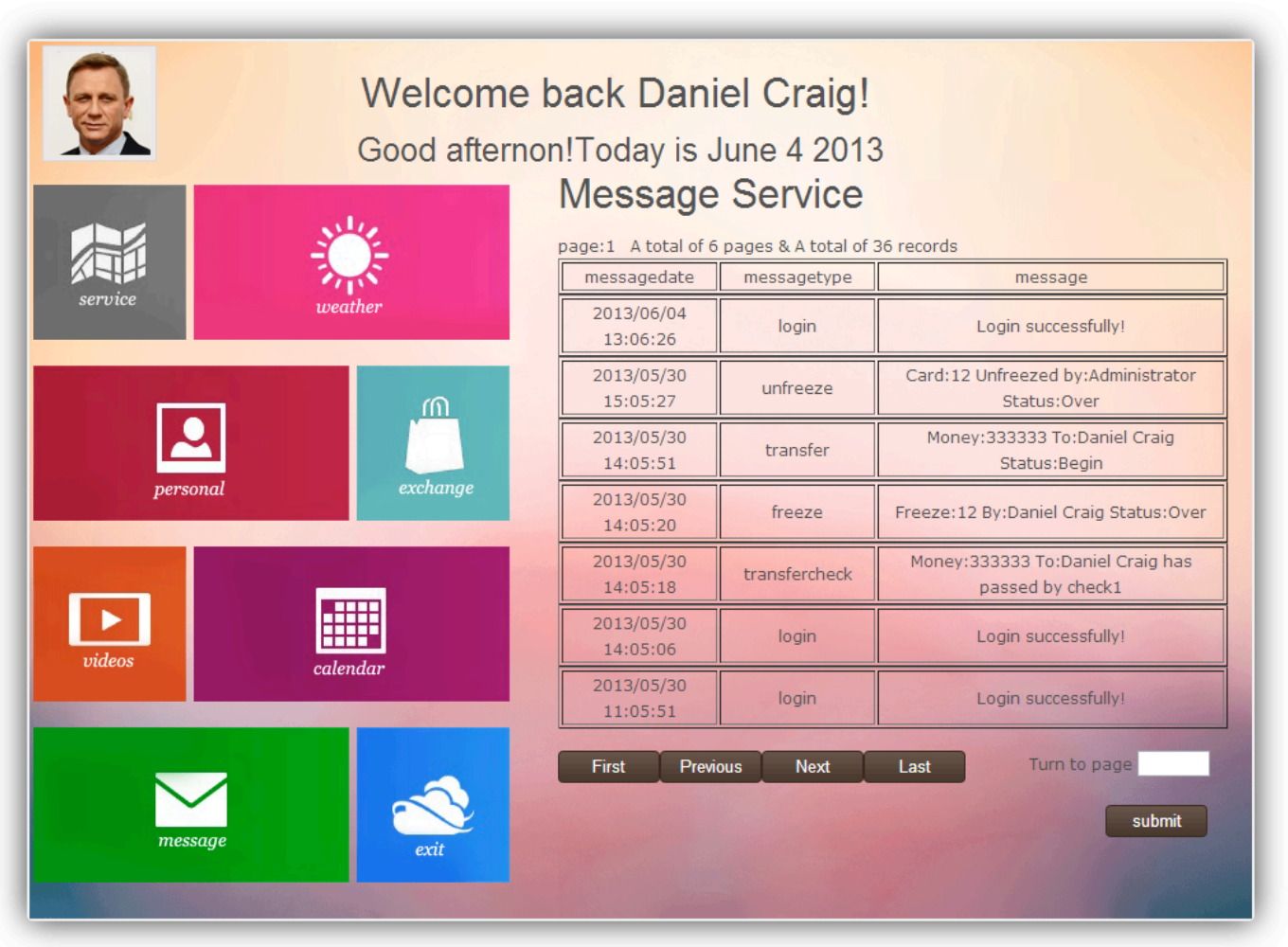

Fig. (8). status query of personal online bank.

user for checking, login, investment and payment is also included in this part. Sequence chart is shown in Fig. (7).

From Fig. (7), it is obvious that users can monitor if the fund has been approved by Browser. After user filled the forms, and confirmed to submit, send a request to transfer, then transfer will generate a transaction id which will exist through the whole transaction flow, and the id will be sent to check1 on the approval flow, check 1 finished approval, it will send a message back to user, similarly, after check 2 and check 3 finish the same task, they will send a final status message back to user to tell him the transaction has been succeeded, and he will get the points as well. When user finds any problems, they can as well stop the transaction under the help from different check which is called Cancel check. After the cancel, information about the transaction cannot be gotten by followed checker. The message that the transaction has been finished is shown in Fig. (8). 


\section{CONCLUSION}

This system specifically introduced the implementation and design of the personal online bank. In the design of systemic framework flowchart, it is easy to see that the whole system architecture is main workflow and is very important to the system. In the implementation and design of the key functions, it mainly explained the application of JSSM in each functional model; include Jquery asynchronous verification, $\mathrm{c}$ tag in classification approval process and application of Metro technology of Windows in jQuery EasyUI interface. This system has passed the built-in-test and the property is very stable. Practice has proved that the hierarchical structure of this system is very clear and simple, and it decreased the coupling of each layer, increased the modularization development effect of the system. It sufficiently embodied the advantage of JSSM. At present, the implementation effect of the system is very favorable, and has been in the built-in-test operation in some bank, and it has got high praise from customers.

\section{CONFLICT OF INTEREST}

The author confirms that this article content has no conflict of interest.

\section{ACKNOWLEDGEMENTS}

Declared none.

\section{REFERENCES}

[1] G. Booch, "Uml user guide (2nd ed)", America: Addison Wesley/Pearson, 2009.

[2] D. Alur, "The J2EE core pattern" America: Addison Wesley/Pearson, 2007.

[3] Z. Li, Z. W. Xi, "Design and implementation of fixed assets management system based on JavaEE", Computer Engineering and Design, vol. 30, pp. 3797-3800, August 2009.

[4] Z. Li, "Design and realization of personal internet banking system based on multi-tier architect" Journal of Applied Sciences, vol. 13, pp. 4386-4392, Nove 2013.

[5] S. J. Metsker, W. C. Wake, "Design Patterns in Java," America: Addison Wesley, 2009.

[6] Z. Li, "Design and realization of car rental managerment system based on AJAX+SSH", Information Technology Journal, vol. 12, pp. 2756-2761, July 2013.

[7] E. Gamma, R. Helm, R. Johnson, J. Vlissides, "Design patterns: elements of reusable object-oriented software," America: Addison Wesley/Pearson, 2009.

[8] H. Jiang, Y. Yin, X. Ban, "Struts framework application based on SOA", Computer Engineering, vol. 35, no. 01, pp. 21-23, 2009.

[9] G. guo, D. Xie, L. Chen, "Design and implementation of teaching support system based on Struts-Spring-Hibernate integration architecture", Computer Engineering and Design, vol. 30, pp. 31113116, July 2009.

Received: September 22, 2014

Revised: November 30, 2014

Accepted: December 02, 2014

(c) Zhang Li; Licensee Bentham Open.

This is an open access article licensed under the terms of the Creative Commons Attribution Non-Commercial License (http://creativecommons.org/licenses/by-nc/3.0/) which permits unrestricted, non-commercial use, distribution and reproduction in any medium, provided the work is properly cited. 